\title{
The role of nitric oxide synthases in pemphigus vulgaris in a mouse model
}

\author{
M. Marquina, A. España, M. Fernández-Galar and M.J. López-Zabalza* \\ Departments of Dermatology and *Biochemistry, University Clinic of Navarra, School \\ of Medicine, University of Navarra, P.O. 4209, Pamplona 31080, Spain
}

\section{SUMMARY}

Background: Pemphigus vulgaris (PV) is a blistering autoimmune disease characterized by IgG autoantibodies against desmoglein 3. Nitric oxide synthases (NOS) may contribute to the increase of inflammation in tissues by the generation of nitrotyrosine residues (NTR).

Objectives: To investigate whether the production of NTR mediated by NOS may participate in the development of inflammation and acantholysis in PV.

Methods: Mice were pretreated or not with NOS, tyrosine-kinase (TK) or nuclear factor (NF)- $\kappa \mathrm{B}$ inhibitors, and then injected with PV-IgG. PV manifestations were examined in all mice. The expression of NTR, constitutive NOS (cNOS) [endothelial NOS (eNOS) and neuronal NOS (nNOS)], inducible NOS (iNOS) and NF- $\kappa \mathrm{B}$ factor were studied in epidermis of mice using immunohistochemical techniques.

Results: After PV-IgG injection, expressions of NTR, iNOS, eNOS and nNOS increased in acantholytic cells, as did nuclear translocation of NF- $\kappa \mathrm{B}$ in the basal cells of the epidermis. Pretreatment of mice with inhibitors of TK, nNOS and nonselective NOS, completely prevented NTR expression and the clinical and histological findings of PV in mice. TK inhibitor genistein inhibited both nNOS and iNOS expression on the membrane of basal keratinocytes, and nuclear translocation of NF- $\mathrm{KB}$.

Conclusions: Upregulation of cNOS and iNOS, NTR generation and nuclear translocation of NF-KB may contribute to increased inflammation and tissue damage in PV lesions. The absence of the clinical and histological findings of PV and NTR expression in mice injected with PV-IgG, through pretreatment with TK and nNOS inhibitors, provides compelling evidence that these signalling molecules should be considered as potential therapeutic targets in PV. 
Pemphigus vulgaris (PV) is a blistering autoimmune skin disease, characterized by IgG autoantibodies against desmoglein (Dsg) 3 and Dsg $1 .{ }^{1-3}$ Several studies have shown that PV-IgG binding to Dsg induces an activation of several intracellular signalling pathways, leading to phosphorylation of desmosomal proteins by protein kinases and the dissociation of cell- cell attachment. ${ }^{4}$ We have recently demonstrated in vivo the participation of tyrosine kinases (TK) and the phosphoinositide signalling pathway in acantholysis in PV using the transfer mouse model. ${ }^{5}$ These observations provide strong support for the role of protein phosphorylation by protein kinases in the molecular mechanism of acantholysis.

Nitric oxide (NO) plays an important role in the physiological regulation of the human body. ${ }^{6,7}$ Also, it may be involved in inflammatory skin diseases. ${ }^{8-12} \mathrm{NO}$ is formed by nitric oxide synthase (NOS) enzymes. ${ }^{13}$ Isomeric forms of NOS have been described. Two of these are constitutively expressed in some tissues as endothelial (eNOS) and neuronal (nNOS) isoforms, whereas another is an inducible enzyme (iNOS). ${ }^{14}$ All NOS isoforms have been detected in several cells, including keratinocytes. ${ }^{15} \mathrm{NO}$ reacts in the cell with the superoxide radical $\left(\mathrm{O}^{-}\right)$, yielding peroxynitrite, an unstable metabolite that rapidly nitrates tyrosine residues (NTR) on proteins to form the stable end product nitrotyrosine. $^{12}$

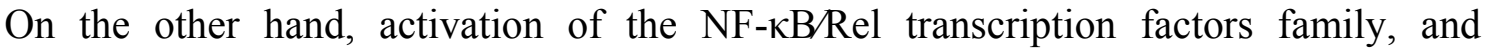
subsequent nuclear translocation of cytoplasmic complexes, plays a key role in inflammation through its ability to induce transcription of proinflammatory genes. ${ }^{16} \mathrm{NF}$ $\mathrm{KB}$ may induce the synthesis of cytokines, chemokines, adhesion molecules, matrix metalloproteinases, COX-2 and iNOS. ${ }^{17,18}$

Currently, in vivo experiments using the iNOS inhibitor $1400 \mathrm{~W},{ }^{19}$ the eNOS inhibitor L-NIO ${ }^{20}$ the nNOS inhibitor SMTC, ${ }^{21}$ the nonselective NOS inhibitor L-NMMA ${ }^{22}$ and the NF- $\kappa \mathrm{B}$ inhibitor parthenolide ${ }^{23}$ have been successfully employed to explore the role of these signalling molecules in several inflammatory diseases.

Although some NOS isoforms and NF- $\mathrm{BB}$ have been implicated in the mechanism of inflammation in animal models, the role of these molecules in PV has not yet been explored. Therefore, the aim of the present study was to identify if NOS isoforms take part in acantholysis of $\mathrm{PV}$, and if so, to determine their role in this autoimmune blistering disease using the passive transfer mouse model.

\section{MATERIALS AND METHODS}

\section{Human sera}

Serum samples were obtained by plasmapheresis from three patients with mucocutaneous PV, during active disease states, and from a healthy donor (normal human serum, NHS). All patients gave signed consent to use their sera for experimental studies. Patients and control sera were tested by indirect immunofluorescence (IF) using monkey oesophagus as tissue substrate. The immunological characteristics of these sera are presented in Table 1. The ethics committee of the University Clinic of Navarra approved the study. 


\section{IgG purification}

IgG fractions from the PV patients and the normal human donor were prepared as previously described. ${ }^{24}$ Briefly, IgG fractions were precipitated with $50 \%$ ammonium sulfate followed by affinity chromatography on Staphylococcus protein A conjugated to agarose beads. Bounded IgG was eluted with $0.2 \mathrm{~mol} \mathrm{~L}^{-1}$ glycine $\mathrm{HCl}, \mathrm{pH} \mathrm{3}$, dialysed extensively against phosphate-buffered saline (PBS), $\mathrm{pH} 7.4$, concentrated by ultrafiltration (Amicon, Beverly, MA, U.S.A.), filter-sterilized, and stored at $-70{ }^{\circ} \mathrm{C}$ until use. Protein concentration was determined by Bradford assay. ${ }^{25} \mathrm{IgG}$ concentration in each fraction was estimated by nephelometry using goat antihuman IgG (Beckman Array 360 System, Holliston, MA, U.S.A.).

\section{Detection of anti-Dsg1 and anti-Dsg3 antibodies by immunoprecipitation}

The anti-Dsg1 and anti-Dsg3 activity of the PV and NHS sera was assayed by immunoprecipitation of recombinant Dsg3 (rDsg) 3 and Dsg1. ${ }^{26}$ Three microlitres of each sera were incubated with $3 \mu \mathrm{g}$ of $\mathrm{rDsg} 1$ and $\mathrm{rDsg} 3$ for $1 \mathrm{~h}$ at room temperature. Protein A conjugated agarose beads were added and subjected to extensive washing with $0.1 \%$ Triton X-100 in Tris-buffered saline (TBS) containing $3 \mathrm{mmol} \mathrm{L}{ }^{-1}$ of calcium prior to elution of the immunoprecipitates from the beads with Laemmli sample buffer [2\% sodium dodecyl sulphate (SDS) $0.1 \mathrm{~mol} \mathrm{~L}^{-1}$ Tris, $\mathrm{pH}$ 6.8]. Immunoprecipitates were separated by $10 \%$ SDS-polyacrylamide gel electrophoresis, transferred to nitrocellulose membrane, and probed by Western blot analysis using rabbit antihuman Dsg1 and antihuman Dsg3 primary antibodies $(1: 2000)$ and horseradish peroxidaseconjugated goat antirabbit IgG secondary antibodies $(1: 3000)$. Immunoreactants were developed with the enhanced chemiluminiscence reaction (ECL-Plus system; Amersham Pharmacia Biotech, Amersham, Bucks, U.K.).

\section{Detection of anti-Dsg1 and anti-Dsg3 antibodies by enzyme-linked immunosorbent assay}

PV and NHS sera were tested for Dsg1 and Dsg3 by a commercially available enzymelinked immunosorbent assay (ELISA) kit following the manufacturer's recommendations (MBL Naka-Ku, Nagoya, 460-002, Japan). The ELISA results were taken as: negative ( $\leq 9$ units), indeterminate (10-20 units) and positive ( $>20$ units).

\section{Testing IgG pathogenicity using the passive transfer animal model}

C57BL/6J mice were obtained from The Jackson Lab (Bar Harbor, ME, U.S.A.). The study was performed in 24-48-h-old neonatal mice (weighing 1.5-2.0 g) from a colony maintained at the Centre of Animal Control at the University of Navarra. Each IgG fraction was tested for pathogenicity by passive transfer experiments as previously described. ${ }^{24} \mathrm{IgG}$ from all three PV sera and NHS were injected intradermally into neonatal mice $\left(2 \mathrm{mg} \mathrm{g}^{-1}\right)(\mathrm{n}=3$ for each $\mathrm{IgG})$ and evaluated $14 \mathrm{~h}$ later for evidence of skin 
blisters. Following examination of the skin for blisters, animals were sacrificed and serum was collected for indirect IF assay using monkey oesophagus as substrate. Clinical activity in mice was evaluated by the presence of Nikolsky's sign (Ns), through pinching the injected skin, and according to the following scale: no spontaneous disease and negative Ns $(0)$, no spontaneous disease and slight Ns $(1+)$, slight spontaneous disease and slight Ns $(2+)$ and important spontaneous disease and positive Ns $(3+)$. Skin biopsies from each animal included lesional skin samples for routine histological examination by haematoxylin and eosin and immunohistochemical staining, and perilesional skin samples for direct IF studies. Also, using the three PV sera and the serum from the healthy donor we scored the histological findings from the mice using the following scale: (0), no acantholysis; (1+), acantholysis affecting $<25 \%$ of the epidermis; $(2+)$, acantholysis affecting between $25 \%$ and $50 \%$ of the epidermis; $(3+)$, acantholysis affecting $>75 \%$ of the epidermis.

\section{Administration of inhibitors}

Each inhibitor was administered to mice by intradermal injection $2 \mathrm{~h}$ before intradermal injections of PV-IgG. Inhibitors were diluted in PBS and injected into mice $(\mathrm{n}=3$ for each inhibitor) at the following doses based on in vivo studies reported elsewhere: TK inhibitor genistein, $500 \mu \mathrm{g} \mathrm{g}^{-1}$ body weight (Sigma, St Louis, MO U.S.A., G6649); ${ }^{5}$ iNOS inhibitor $1400 \mathrm{~W}, 3 \mu \mathrm{g} \mathrm{g} \mathrm{g}^{-1}$ body weight (Calbiochem, Darmstadt, Germany, 100050); ${ }^{19}$ eNOS inhibitor L-NIO [L-N ${ }^{5}$-(1-Iminoethyl) ornitine dihydrochloride], 30 $\mu \mathrm{g} \mathrm{\textrm {g } ^ { - 1 }}$ body weight (Calbiochem, 400600); ${ }^{20} \mathrm{nNOS}$ inhibitor SMTC (S-methyl-Lthiocitruline dihdrochloride), $50 \mu \mathrm{g} \mathrm{g}^{-1}$ body weight (Calbiochem, 472804); ${ }^{21}$ nonselective NOS inhibitor L-NMMA [N(G) monomethyl-L-arginine], $0.5 \mu \mathrm{g} \mathrm{g}^{-1}$ body weight (Calbiochem, 475886); ${ }^{22} \mathrm{NF}-\mathrm{KB}$ inhibitor parthenolide, $6 \mu \mathrm{g} \mathrm{g}^{-1}$ body weight (Calbiochem, 512732). ${ }^{23}$

\section{Immunohistochemical staining}

Paraffin sections 5- $\mu \mathrm{m}$ thick were mounted on slides coated with Vectabond (SP-1800; Vector Laboratories, Burlingame, CA, U.S.A.). These sections were dewaxed with xylene and rehydrated with graded ethanol. Endogenous peroxidase activity was blocked with 3\% hydrogen peroxidase for $10 \mathrm{~min}$. Before the immunohistochemical analyses were performed, all antibodies except eNOS required antigen retrieval. All sections were placed in a citrate buffer $0.01 \mathrm{~mol} \mathrm{~L}^{-1}$ ( $\mathrm{pH}$ 6.0) and heated in a microwave oven (Balay W-2112, 1150-700W; Madrid, Spain) for 15 min at maximum power (1150 $\mathrm{W})$ and for $15 \mathrm{~min}$ at medium power $(900 \mathrm{~W})$. Background blocking was performed with 1 : 20 normal goat serum (Dako, Glostrup, Denmark) prior to incubation with specific antiserum. Tissue sections were incubated with different polyclonal antibodies specific for: NTR (kindly supplied by Dr JoséRodrigo), ${ }^{27}$ diluted to $1: 1000$, without microwave; iNOS (Santa Cruz Biotechnology, Santa Cruz, CA, U.S.A., sc-651), diluted to 1 : 100, with microwave; eNOS (Transduction Laboratories, San Jose, CA, U.S.A., N30030-610298), diluted to $1: 200$, without microwave; and nNOS (Chemicon International Inc., Temecula, CA, U.S.A., AB1632), diluted to $1: 200$, with microwave; NF- $\kappa$ B (p65) (Delta Biolabs, Campbell, CA, U.S.A., DB033), diluted to 1 : 500, with 
microwave. Sections were incubated overnight at $4{ }^{\circ} \mathrm{C}$ with the primary antiserum. The detection system used was the Envision method (Dako, K4011), consisting of a goat antirabbit immunoglobulin secondary antibody coupled to a peroxidaselabelled dextran polymer. Sections were incubated with this reagent for $30 \mathrm{~min}$ at room temperature and successively washed in TBS for $5 \mathrm{~min}$ and in $0.1 \mathrm{~mol} \mathrm{~L}^{-1}$ sodium acetate/acetic acid buffer, $\mathrm{pH}$ 6.0, for $5 \mathrm{~min}$. Peroxidase activity was revealed using $0.03 \%$ 3,3'diaminobenzidine (Sigma), which shows black colour, or Vector Vip (Vector Laboratories, SK-4600), which shows purple colour. ${ }^{28}$ Both were in $0.1 \mathrm{~mol} \mathrm{~L}^{-1}$ sodium acetate/acetic acid buffer, $\mathrm{pH} 6.0$, containing 2.5\% nickel ammonium sulfate, $0.2 \%$-Dglucose, $0.04 \%$ ammonium chloride and $0.01 \%$ glucose oxidase. The reaction was stopped by a wash in TBS. Finally, sections were lightly counterstained with haematoxylin, dehydrated and mounted with DPX.

The results of immunohistochemical expression for each of the three PV sera were assessed on a scale of 0 to $3+:(0)$, no expression; $(1+)$, patchy and weak staining close to the membranes of acantholytic cells of the floor/or base of the blister; $(2+)$, moderate linear staining at the same site; $(3+)$, clear and strong staining at the same site.

\section{RESULTS}

Skin lesions in mice after pemphigus vulgaris serum and normal human serum injection

Results were similar after injection of each of the three PV sera in mice $(n=3)$ (see Table 2). The administration of PV-IgG reproduced the disease in a localized form $14 \mathrm{~h}$ after injection in both clinical ( $3+$ in all three mice) and histopathological form $(3+$ in all mice) (Fig. 1a, b). The administration of purified NHS-IgG to mice did not show clinical or histological detachment (Fig. 1h, i), and no staining for IgG by direct and indirect IF assays was detected (data not shown).

\section{Expression of NTR, iNOS, eNOS, nNOS and NF-kB (p65) in pemphigus vulgaris acantholytic cells after pemphigus vulgaris serum and normal human serum injection}

After PV-IgG administration to mice, expression of NTR was increased in acantholytic cells both at the base and at the roof of the blisters (2+ to 3+) (Fig. 1c) (Table 2). Staining for iNOS was also found in the acantholytic cells at the base and at the roof of the blisters (2+) (Fig. 1d). Surprisingly, the expression of cNOS was observed in acantholytic cells both at the base and at the roof of the blisters as well, with a stronger staining for nNOS $(2+$ to $3+$ ) (Fig. 1f) than for eNOS (1+ to 2+) (Fig. 1e). Nuclear translocation of NF- $\mathrm{kB}$ was observed only in basal keratinocytes and acantholytic cells (Fig. 1g) (Table 2). It is interesting to note that the expression of NTR, iNOS, eNOS and nNOS was evident from the beginning of the acantholytic process even when blisters were not fully formed (Fig. 2a-d). 
After NHS-IgG injection into the mice no expression of NTR was observed (Fig. 1j). Furthermore, we found only scattered and very slight basal cell cytoplasmic staining for nNOS (Fig. 1m), and staining for eNOS in the epidermis was absent (Fig. 11). Slight staining for iNOS was observed in the nucleus of basal and suprabasal cells (Fig. 1k), and NF- $\mathrm{KB}$ (p65) was detected only within the cytoplasm of basal and suprabasal keratinocytes (Fig. 1n).

\section{Effects of pemphigus vulgaris serum in mice pretreated with inhibitors}

Clinical and histological PV manifestations after PV-IgG injection were prevented by pretreatment with the TK inihibitor genistein (Fig. 3a, b), the nNOS inhibitor SMTC (Fig. 4a, f) and the nonselective NOS inhibitor L-NMMA (Fig. 4b, g). In contrast, pretreatment of mice with the eNOS inhibitor L-NIO (Fig. 4c, h), the iNOS inhibitor 1400W (Fig. 4d, i) and the NF-KB inhibitor parthenolide (Fig. 4e, j) did not prevent clinical skin lesions (Table 2). Direct IF staining of biopsies demonstrated pericellular surface staining for IgG in both groups of mice (PV-IgG and inhibitors plus PV-IgG), demonstrating that pretreatment with inhibitors did not affect the binding of the pathogenic IgG to Dsg3 (data no shown). Indirect IF revealed circulating IgG with a pericellular staining pattern with titres ranging between $1: 20$ and $1: 80$ (data not shown).

The skin of the mice injected with PV sera and pretreated with TK, nNOS or nonselective NOS inhibitors did not exhibit expression of NTR in the epidermis (Figs $3 \mathrm{~d}$ and $4 \mathrm{k}, 1)$. In contrast, only a weak decreased staining for NTR was found in mice injected with PV-IgG and pretreated with eNOS, iNOS and NF- $\kappa \mathrm{B}$ inhibitors $(1+$ to $2+$, $1+$ and $1+$, respectively) (Fig. $4 \mathrm{~m}-\mathrm{o}$ ). Interestingly, NF- $\mathrm{KB}$ nuclear translocation, and iNOS and nNOS expression on the membrane of basal keratinocytes were prevented by the pretreatment with TK inhibitor genistein. Only a scattered and very slight basal cell cytoplasmic staining for nNOS was observed (Fig. 3c, e, f).

\section{DISCUSSION}

Acantholysis in PV is a complex immunological process in which several mechanisms take part. On the one hand, PV patients present Dsg-3-specific T cells, which may trigger the response of B cells, yielding the production of autoantibodies against Dsg3 andor Dsg1. ${ }^{29}$ PV-IgG binding to Dsg may trigger the acantholysis phenomenon in suprabasal keratinocytes through several mechanisms. These include: physical disruption of adhesion by blocking the adhesive interface of the Dsg (steric hindrance theory) $;^{30}$ the depletion of membranal Dsg pool and formation of aberrant and weak desmosomes, thereby causing cell-cell separation; ${ }^{31}$ activation of intracellular signal transduction pathways leading to a negative influence on the adhesive function of Dsg; ${ }^{4,32-36}$ separation of keratinocytes due to cytoskeleton shrinkage (basal cell shrinkage hypothesis); ${ }^{37}$ and apoptosis as a process of keratinocyte death. ${ }^{38-41}$ These hypotheses have been complemented with the Dsg compensation concept to understand how acantholysis in PV takes place. ${ }^{42}$ Also, we have recently demonstrated in vivo the involvement of the phosphoinositide signalling pathway using the transfer mouse 
model. ${ }^{5}$ This provides a strong support for the role of the phosphorylation of proteins by protein kinases in the molecular mechanism of acantholysis.

In this study we investigated the expression of NOS isoforms and NTR and the nuclear translocation of NF-KB in acantholytic cells in a mouse model of PV. All of these molecules were expressed in PV lesions, and nuclear translocation of NF-KB was detected in basal cells of the epidermis in mice after PV-IgG injection. These findings are particularly interesting as they indicate an additional contribution of inflammatory mediators in PV. Although a possible role for NOS and NF-KB in several autoimmune disorders has been demonstrated, ${ }^{13,18}$ the presence of these signalling molecules in acantholytic cells of PV in vivo has not been previously described. Only isolated in vitro studies have detected the presence of iNOS in PV. ${ }^{43}$ Also, recent work from Brazil has demonstrated that pemphigus patients display increased serum NO levels associated with increased iNOS expression in the affected skin. ${ }^{44}$ What could trigger the increased expression of these molecules in PV lesions in our mouse model, and how could they work?

Multiple factors are important in determining the dual role of NO in physiology and pathophysiology. ${ }^{13}$ Among these, the local concentration of NO is an important determinant of cytotoxicity. The picomolar amounts of NO produced by cNOS isoforms are sufficient for intra- and intercellular signalling, including homeostasis of the microvasculature, while the micromolar concentrations generated by high-output iNOS are microbicidal as well as pro-inflammatory and so damage the surrounding cells and tissues. ${ }^{13,45,46}$ Recent evidence has demonstrated that the expression of cNOS (eNOS and nNOS) is not restricted to endothelial and neuronal cells ${ }^{47,48}$ and that the expression of the eNOS and nNOS genes may be regulated by a variety of physiological and pathological stimuli. ${ }^{49}$ In this sense, the presence of NTR specifically on acantholytic cell membranes together with iNOS, eNOS and nNOS staining is particularly interesting. Although it is known that iNOS is a more potent producer of NO than cNOS (eNOS and nNOS), ${ }^{13}$ our findings suggest an important and additional role of nNOS in the nitration mechanisms in PV. Moreover, we have previously demonstrated that the pretreatment with a calmodulin-antagonist also prevented acantholysis. This finding is consistent with the participation of a calcium-calmodulindependent cNOS isoform as in nNOS, in acantholysis of PV. ${ }^{5}$ In an inflammatory environment, as observed in PV lesions, a high production of $\mathrm{NO}$ may interact with superoxide radical $\left(\mathrm{O}^{-}\right)$to produce the tissue-damaging peroxynitrite $\left(\mathrm{ONOO}^{-}\right)$, an unstable metabolite that rapidly nitrates tyrosine residues in proteins on cells. ${ }^{50}$ There is also evidence that specific proteins could be nitrated by NO synthesized by cNOS, in the same way that they are nitrated by a peroxinitrite generator. ${ }^{51}$ In line with this, protein tyrosine nitration by NO derived from nNOS has also been demonstrated to take part in the pathogenesis of hepatic encephalopathy. ${ }^{52}$

A further relevant finding from our study is related to the clinical, histological and immunohistochemical results when inhibitors were used. NF- $\kappa \mathrm{B}$, eNOS and iNOS inhibitors did not prevent the PV acantholytic process in mice, and was associated with a weak decreased expression of NTR in the epidermis. However, nNOS and nonspecific NOS inhibitors prevented PV-IgG-induced acantholysis, with no expression of NTR. These results demonstrate that synthesis of NO by nNOS, and the subsequent NTR production, may have a direct role in promoting the acantholytic process in $\mathrm{PV}$, in 
addition to cooperating in the inflammation of epidermis as well as in the plasminogen plasmin $^{53}$ and complement systems. ${ }^{54}$

The reason why the inhibitor of nNOS and the nonspecific inhibitor of NOS pretreatment abolished clinical lesions in mice is not clear to us. Recently, upregulation of nNOS in HaCaT cells has been achieved with epidermal growth factor receptor (EGFR) ligands, and this upregulation was completely inhibited by EGFR antagonist. ${ }^{47}$ Also, it has been demonstrated that PV-IgG induces EGFR activation, and EGFR inhibition prevents acantholysis. ${ }^{55}$ These issues are consistent with our observation that the TK inhibitor genistein inhibited nNOS expression. Moreover, it is interesting to note that NTR expression in the epidermis was prevented by pretreatment with the nNOS inhibitor, thus showing that tyrosine nitration of proteins by nNOS is involved in PV. In this sense, nNOS may participate in PV through signalling events, which allow specific changes leading to acantholysis. On the other hand, Mishra and DelivoriaPapadopoulos ${ }^{56}$ have recently reported that the NO derived from nNOS may contribute to apoptosis, a process associated with acantholysis in PV. ${ }^{39-41}$ Nevertheless, more studies are necessary to understand how nNOS works in PV lesions, and why its presence is necessary for the acantholytic phenomenon to develop.

In addition, our study demonstrates nuclear translocation of NF-KB and iNOS expression in basal acantholytic cells in PV lesions. However, the inhibition of these related signalling events did not completely prevent both acantholysis and NTR expression in epidermis. This may indicate that the NO produced by iNOS is not essential in PV acantholysis in our model. Consequently, its function in the PV blistering process may be related only to the creation of an inflammatory environment as has been described in other autoimmune diseases, ${ }^{17,18}$ but with no function on the adhesion of keratinocytes. In other immunological diseases, such as toxic epidermal necrolysis and Stevens-Johnson syndrome, tissue damage may be observed by upregulation of iNOS. In these cases, large amounts of NO formed by iNOS from inflammatory cells may cause the epidermal apoptosis and necrosis. ${ }^{57}$

In summary, we demonstrate an increased expression of NTR, iNOS, eNOS and nNOS, and nuclear translocation of NF- $\mathrm{BB}$ in acantholytic cells of PV. The absence of clinical and histological findings of PV after pretreatment with TK and nNOS inhibitors in our model provide compelling evidence that nNOS, in addition to TK, should also be considered as a potential therapeutic target in PV. Nevertheless, further studies will be needed to reveal the exact contribution of the inflammatory mediators and specifically that of nNOS in the development of PV.

\section{Acknowledgments}

We would like to thank Professor Esteban Santiago for critical reading of the manuscript. This work has been supported by a FIS grant from Ministry of Health of Spain (PI021217). 


\section{REFERENCES}

1. Korman NJ. Pemphigus. J Am Acad Dermatol 1988; 18:1219-38.

2. Korman N, Eyre RW, Klau-Kovtun V, Stanley JR. Demonstration of an adhering junction molecule (plakoglobin) in the autoantigen of pemphigus foliaceus and pemphigus vulgaris. N Engl J Med 1985; 321:631-5.

3. Eyre RW, Stanley JR. Identification of pemphigus vulgaris antigen extracted from normal human epidermis and comparison with pemphigus foliaceus antigen. J Clin Invest 1988; 81:807-12.

4. Kitajima Y, Aoyama Y, Seishima M. Transmembrane signaling for adhesive regulation of desmosomes and hemidesmosomes, and for cell-cell detachment induced by pemphigus IgG in cultured keratinocytes: involvement of protein kinase C. J Investig Dermatol Symp Proc 1999; 4:137-44.

5. Sánchez-Carpintero I, España A, Pelacho B et al. In vivo blockade of pemphigus vulgaris acantholysis by inhibition of intracellular signal transduction cascades. Br J Dermatol 2004; 151:565-70.

6. Schwentker A, Vodovotz Y, Weller R, Billiar TR. Nitric oxide and wound repair: role of cytokines? Nitric Oxide 2002; 7:1-10.

7. Romero-Graillet $\mathrm{C}$, Aberdam $\mathrm{E}$, Clement $\mathrm{M}$ et al. Nitric oxide produced by ultraviolet-irradiated keratinocytes stimulates melanogenesis. J Clin Invest 1997; 99:635-42.

8. Bruch-Gerharz D, Fehsel K, Suschek C et al. A proinflammatory activity of interleukin 8 in human skin: expression of the inducible nitric oxide synthase in psoriasis lesions and cultured keratinocytes. J Exp Med 1996; 184:2007-12.

9. Becherel PA, Chosidow O, Le Goff $\mathrm{L}$ et al. Inducible nitric oxide synthase and proinflammatory cytokine expression by human keratinocytes during acute urticaria. Mol Med 1997; 3:686-94.

10. Rowe A, Farrele AM, Bunker CB. Constitutive endothelial and inducible nitric oxide synthase in inflammatory dermatoses. Br J Dermatol 1997; 136:18-23.

11. Chan J, Tanaka K, Carroll D et al. Effects of nitric oxide synthase inhibitors on murine infections with Mycobacterium tuberculosis. Infect Immun 1995; 63:73640.

12. Schön T, Hernandez-Pando RH, Negesse $\mathrm{Y}$ et al. Expression of inducible nitric oxide synthase and nitrotyrosine in borderline leprosy lesions. Br J Dermatol 2001; 145:809-15.

13. Abramson SB, Amin AR, Clancy RM, Attur M. The role of nitric oxide in tissue destruction. Best Pract Res Clin Rheumatol 2001; 15:831-45.

14. Alderton WK, Cooper CE, Knowles RG. Nitric oxide synthases: structure, function and inhibition. Biochem J 2001; 357:593-615.

15. Lyons CR. The role of nitric oxide in inflammation. Adv Immunol 1995; 60:32371.

16. Baldwin AS Jr. The NF-xB and I-xB proteins: new discoveries and insights. Annu Rev Immunol 1996; 14:649-83.

17. Janssen-Heininger YMW, Poynter ME, Baeuerle PA. Recent advances towards understanding redox mechanisms in the activation of nuclear factor $\mathrm{xB}$. Free Radic Biol Med 2000; 28:1317-27.

18. Tak PP, Firestein GS. NF-xB: a key role in inflammatory diseases. J Clin Invest 2001; 107:7-11. 
19. Parker JU, Qi W-N, Liu JQ et al. Inhibition of iNOS attenuates skeletal muscle reperfusion injury in extracellular superoxide dismutase knockout mice. Microsurgery 2005; 25:606-13.

20. Benamar K, Yondorf MZ, Kon D et al. Role of the nitric-oxide synthase isoforms during morphine-induced hyperthermia in rats. J Pharmacol Exp Ther 2003; 307:219-22.

21. Ishikawa M, Quock RM. Role of nitric-oxide synthase isoforms in nitrous oxide antinociception in mice. J Pharmacol Exp Ther 2003; 306:484-9.

22. Vivancos GG, Parada CA, Ferreira SH. Opposite nociceptive effects of the arginineNO /cGMP pathway stimulation in dermal and subcutaneous tissues. Br J Pharmacol 2003; 138:1351-7.

23. Kozak W, Wrotek S, Kozak A. Pyrogenicity of CpG-DNA in mice: role of interleukin-6, cyclooxygenases, and nuclear factor-xB. Am J Physiol Regul Integr Comp Physiol 2006; 290:R871-80.

24. España A, Diaz LA, Mascaro JM Jr. Mechanisms of acantholysis in pemphigus foliaceus. Clin Immunol Immunopathol 1997; 85:83-9.

25. Bradford MM. A rapid and sensitive method for quantitation of microgram quantities of protein utilizing the principle of proteindye binding. Anal Biochem 1976; 72:248-54.

26. Ding X, Aoki V, Mascaro JM Jr et al. Mucosal and mucocutaneous (generalized) pemphigus vulgaris show distinct autoantibody profiles. J Invest Dermatol 1997; 109:592-6.

27. Uttenthal LO, Alonso D, Fernandez AP et al. Neuronal and inducible nitric oxide synthase and nitrotyrosine immunoreactivities in the cerebral cortex of the aging rat. Microsc Res Tech 1998; 43:75-88.

28. Shu SY, Ju G, Fan LZ. The glucose oxidase-DAB-nickel method in peroxidase histochemistry of the nervous system. Neurosci Lett 1988; 85:169-71.

29. Lin MS, Swartz SJ, Lopez A et al. Development and characterization of desmoglein-3 specific $\mathrm{T}$ cells from patients with pemphigus vulgaris. J Clin Invest 1997; 99:31-40.

30. Shimizu A, Ishiko A, Ota $\mathrm{T}$ et al. IgG binds to desmoglein 3 in desmosomes and causes a desmosomal split without keratin retraction in a pemphigus mouse model. $\mathrm{J}$ Invest Dermatol 2004; 122:1145-53.

31. Calkins C, Setzer SV, Jennings JM et al. Desmoglein endocytosis and desmosome disassembly are coordinated responses to pemphigus autoantibodies. J Biol Chem 2006; 281:7623-34.

32. Kitajima Y, Aoyama Y, Osada K et al. Substrates for phosphorylation by protein kinase $\mathrm{C}$ activated with pemphigus-IgG in cultured keratinocytes (abstract). J Invest Dermatol 1996; 106:847.

33. Seishima M, Esaki C, Osada K et al. Pemphigus IgG, but not bullous pemphigoid IgG, causes a transient increase in intracellular calcium and inositol 1,4,5triphosphate in DJM-1 cells, a squamous carcinoma line. J Invest Dermatol 1995; 104:33-7.

34. Esaki C, Seishima M, Yamada T et al. Pharmacologic evidence for involvement of phospholipase $\mathrm{C}$ in pemphigus IgG-induced inositol 1,4,5-triphosphate generation, intracellular calcium increase, and plasminogen activator secretion in DJM-1 cells, a squamous cell carcinoma line. J Invest Dermatol 1995; 105:329-33.

35. Seishima M, Iwasaki-Bessho $Y$, Itoh $Y$ et al. Phosphatidylcholinespecific phospholipase $\mathrm{C}$, but not phospholipase $\mathrm{D}$, is involved in pemphigus IgG-induced signal transduction. Arch Dermatol Res 1999; 291:606-13. 
36. Osada K, Seishima M, Kitajima Y. Pemphigus IgG activates and translocates protein kinase $\mathrm{C}$ from the cytosol to the particulate/cytoskeleton fractions in human keratinocytes. J Invest Dermatol 1997; 108:482-7.

37. Bystryn JC, Grando SA. A novel explanation for acantholysis in pemphigus vulgaris: the basal cell shrinkage hypothesis. J Am Acad Dermatol 2006; 54:51316.

38. Puviani M, Marconi A, Cozzani E, Pincelli C. Fas ligand in pemphigus sera induces keratinocytes apoptosis through the activation of caspase-8. J Invest Dermatol 2003; 120:164-7.

39. Pelacho B, Natal C, España A et al. Pemphigus vulgaris autoantibodies induce apoptosis in HaCaT keratinocytes. FEBS Lett 2004; 566:6-10.

40. Wang X, Bregegere F, Frusic-Zlotkin M et al. Possible apoptotic mechanism in epidermal cell acantholysis induced by pemphigus vulgaris autoimmunoglobulin. Apoptosis 2004; 9:131-43.

41. Arredondo J, Chernyavsky AI, Karaouni A, Grando SA. Novel mechanisms of target cell death and survival and of therapeutic action of IVIg in pemphigus. Am J Pathol 2005; 167:1531-44.

42. Mahoney MG, Wang Z, Rhotemberger KL et al. Explanations for the clinical and microscopic localization of lesions in pemphigus foliaceus and vulgaris. J Clin Invest 1999; 103:461-8.

43. Baroni A, Buommino E, Paoletti I et al. Pemphigus serum and captopril induce heat shock protein and inducible nitric oxide synthase overexpression, triggering apoptosis in human keratinocytes. Br J Dermatol 2004; 150:1070-80.

44. Siebra MX, Santos MA, Almeida TLP et al. Evidence for the participation of nitric oxide in pemphigus. Braz J Med Biol Res 2006; 39:671-5.

45. Nathan C. Perspectives series: nitric oxide and nitric oxide synthases. Inducible nitric oxide synthase: what difference does it make? J Clin Invest 1997; 100:241723.

46. Christopherson KS, Bredt DS. Perspectives series: nitric oxide and nitric oxide synthases. Nitric oxide in excitable tissues: physiological roles and diseases. J Clin Invest 1997; 100:2424-9.

47. Boissel JP, Ohly D, Bros M et al. The neuronal nitric oxide synthase is upregulated in mouse skin repair and in response to epidermal growth factor in human $\mathrm{HaCaT}$ keratinocytes. J Invest Dermatol 2004; 123:132-9.

48. Baudouin JE, Tachon P. Constitutive nitric oxide synthase is present in normal human keratinocytes. J Invest Dermatol 1996; 106:428-31.

49. Dawson VL, Dawson TM. Nitric oxide in neurodegeneration. Prog Brain Res 1998; 118:215-29.

50. Ischiropoulos H. Biological tyrosine nitration: a pathophysiological function of nitric oxide and reactive oxygen species. Arch Biochem Biophys 1998; 1:1-11.

51. Bengoechea-Alonso MT, Pelacho B, Oses-Prieto JA et al. Regulation of NF-xB activation by protein phosphatase $2 \mathrm{~B}$ and $\mathrm{NO}$, via protein kinase $\mathrm{A}$ activity, in human monocytes. Nitric Oxide 2003; 8:65-74.

52. Görg B, Bidmon HJ, Keitel V et al. Inflammatory cytokines induce protein tyrosine nitration in rat astrocytes. Arch Biochem Biophys 2006; 449:104-14.

53. Seishma M, Satoh S, Nojiri M et al. Pemphigus IgG induces expression of urokinase plasminogen activator receptor on the cell surface of cultured keratinocytes. J Invest Dermatol 1997; 109:650-5.

54. Mascaro JM Jr, España A, Liu Z et al. Mechanisms of acantholysis in pemphigus vulgaris: role of IgG valence. Clin Immunol Immunopathol 1997; 85:90-6. 
55. Frusic-Zlotkin $M$, Raichenberg $D$, Wang $X$ et al. Apoptotic mechanism in pemphigus autoimmunoglobulins-induced acantholysis possible involvement of the EGF receptor. Autoimmunity 2006; 39: 563-75.

56. Mishra OP, Delivoria-Papadopoulos M. Effect of neuronal nitric oxide synthase inhibition on caspase- 9 activity during hypoxia in the cerebral cortex of newborn piglets. Neurosci Lett 2006; 401:81- 5 .

57. Lerner LH, Qureshi AA, Reddy BV, Lerner EA. Nitric oxide synthase in toxic epidermal necrolysis and Stevens-Johnson syndrome. J Invest Dermatol 2000; 114:196-9. 


\begin{tabular}{|c|c|c|c|}
\hline Sera & IP & IIF & ELISA \\
\hline PV1 & Dsg1+ and Dsg3+ & $1: 640$ & Dsg1: 60, Dsg3: 173 \\
\hline PV2 & Dsg1+ and Dsg3+ & $1: 320$ & Dsg1: 189, Dsg3: 77 \\
\hline PV3 & Dsg1+ and Dsg3+ & $1: 640$ & Dsg1: 77, Dsg3: 169 \\
\hline NHS & No bands & Negative & Dsg1: $<20$, Dsg3: $<20$ \\
\hline \multicolumn{4}{|c|}{$\begin{array}{l}\text { Dsg, desmoglein; ELISA, enzyme-linked immunosorbent assay; IIF, } \\
\text { indirect immunofluorecence; IP, immunoprecipitation; NHS, normal } \\
\text { human serum; PV, pemphigus vulgaris }\end{array}$} \\
\hline
\end{tabular}

Table 2. Clinical, histological and immunohistochemical findings after PV-IgG or PV-IgG plus inhibitors

\begin{tabular}{|c|c|c|c|c|c|c|c|}
\hline & $\begin{array}{c}\text { PV } \\
\text { lesions }\end{array}$ & Acantholysis & NTR & iNOS & nNOS & eNOS & NF-xB \\
\hline NHS-IgG & 0 & 0 & 0 & $\begin{array}{l}\text { Nuclear } \\
\text { staining }\end{array}$ & $\begin{array}{c}\text { Slight basal } \\
\text { cell } \\
\text { cytoplasmic } \\
\text { staining }\end{array}$ & 0 & $\begin{array}{c}\text { Cytoplasmic } \\
\text { staining }\end{array}$ \\
\hline PV-IgG & $3+$ & $3+$ & $2+$ to $3+$ & $2+$ & $2+$ to $3+$ & $1+$ to $2+$ & $2+$ to $3+$ \\
\hline SMTC + PV-IgG & 0 & 0 & 0 & ND & ND & ND & ND \\
\hline $\begin{array}{c}\text { L-NMMA + PV- } \\
\text { IgG }\end{array}$ & 0 & 0 & 0 & ND & ND & ND & ND \\
\hline $\mathrm{L}-\mathrm{NIO}+\mathrm{PV}-\mathrm{IgG}$ & $3+$ & $3+$ & $1+$ to $2+$ & ND & ND & ND & ND \\
\hline $1400 \mathrm{~W}+\mathrm{PV}-\mathrm{IgG}$ & $3+$ & $3+$ & $1+$ & ND & ND & ND & ND \\
\hline $\begin{array}{l}\text { Parthenolide + } \\
\text { PV-IgG }\end{array}$ & $3+$ & $3+$ & $1+$ & ND & ND & ND & ND \\
\hline $\begin{array}{c}\text { Genistein + PV- } \\
\text { IgG }\end{array}$ & 0 & 0 & 0 & $\begin{array}{l}\text { Slight } \\
\text { nuclear } \\
\text { staining }\end{array}$ & $\begin{array}{c}\text { Slight basal } \\
\text { cell } \\
\text { cytoplasmic } \\
\text { staining }\end{array}$ & ND & ND \\
\hline
\end{tabular}

PV, pemphigus vulgaris; NTR, nitrotyrosine residues; iNOS, inducible nitric oxide synthase; nNOS, neural nitric oxide synthase; eNOS, endothelial nitric oxide synthase; NF- $\kappa \mathrm{B}$, nuclear factor $\kappa B$; NHS, normal human serum; SMTC, nNOS inhibitor; L-NMMA, nonselective NOS inhibitor; L-NIO, eNOS inhibitor; ND, not done. 


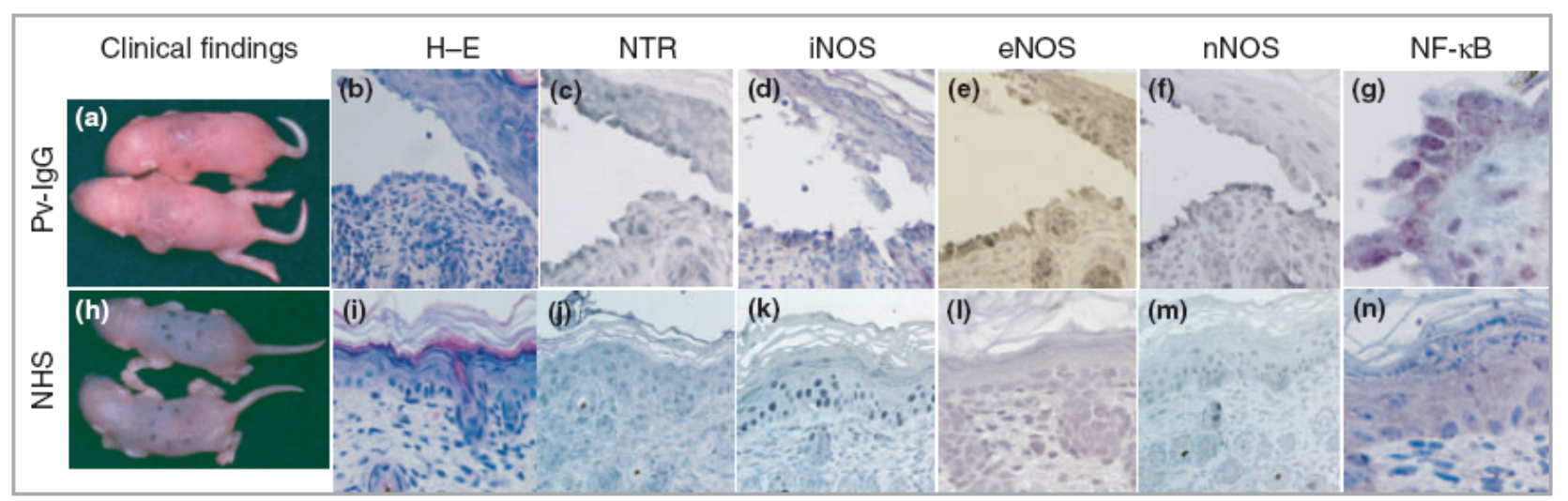

Figure 1. All mice injected with PV-IgG presented skin disease (3+) (positive Nikolsky's sign) (a) and suprabasal blisters $(3+)(\mathrm{b})$. In addition, these mice presented moderate-strong linear staining $(2+$ to $3+$ ) for NTR (arrow) (c) and nNOS (arrow) (f), and moderate linear staining (2+) for iNOS (arrow) (d) in the membrane of the acantholytic cells at the base and the roof of the blisters. However, only weak-moderate staining for eNOS (arrow) was observed (e) with a similar staining pattern. Moderatestrong $(2+$ to $3+)$ nuclear translocation of NF-jB was found in basal cell of epidermis (arrow) (g). Those mice injected with NHS-IgG showed neither clinical lesions (h) nor suprabasal acantholysis (i). Also, staining for NTR (j) and eNOS (1) was absent, and scattered nuclear expression for iNOS $(\mathrm{k})$ was observed. Interestingly, very slight basal cell cytoplasmic staining for nNOS (arrow) (m) was found. No nuclear translocation was detected (n). Figure 2 displays close-up pictures showing how each molecule is expressed. PV-IgG, administration to mice of IgG fraction from PV patients; NHS, administration into mice of IgG fraction from normal human serum; NTR, expression of nitrotyrosine residues; eNOS, expression of endothelial nitric oxide synthase; iNOS, expression of inducible nitric oxide synthase; nNOS, expression of neuronal nitric oxide synthase. Original magnification x $40(\mathrm{~b}-\mathrm{f}, \mathrm{i}-\mathrm{m})$ and $\mathrm{x} 80(\mathrm{~g}, \mathrm{n})$. 

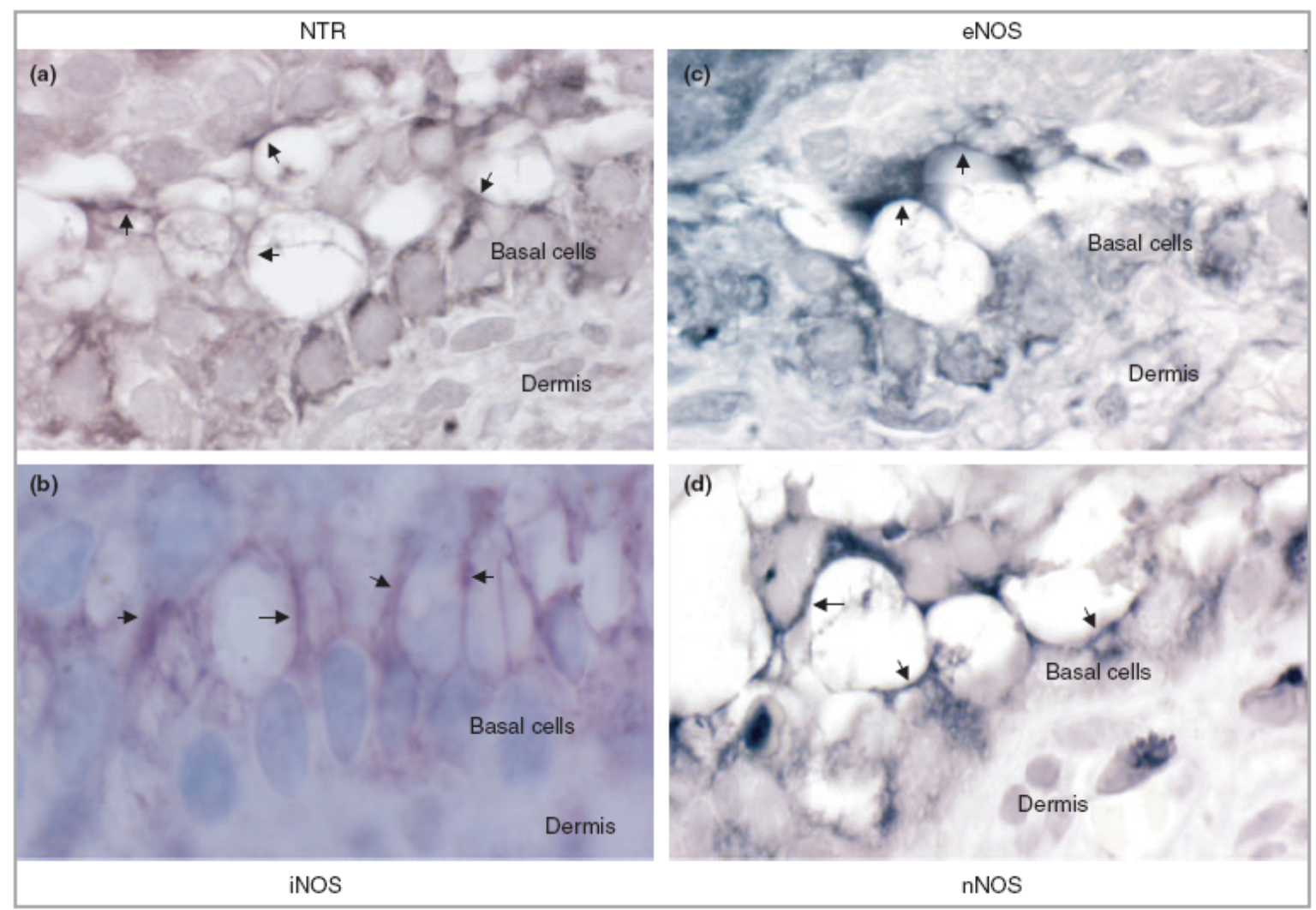

Figure 2. Close-up pictures of Figure 1c-f. It is interesting to note that the expression of NTR (arrow) (a), iNOS (arrow) (b), eNOS (arrow) (c) and nNOS (arrow) (d) was evident from the beginning of the acantholytic process even when blisters were not fully formed. In these cases, the molecules were expressed in the cytoplasm and close to the membrane of keratinocytes during the blistering process. Original magnification x 100 . 


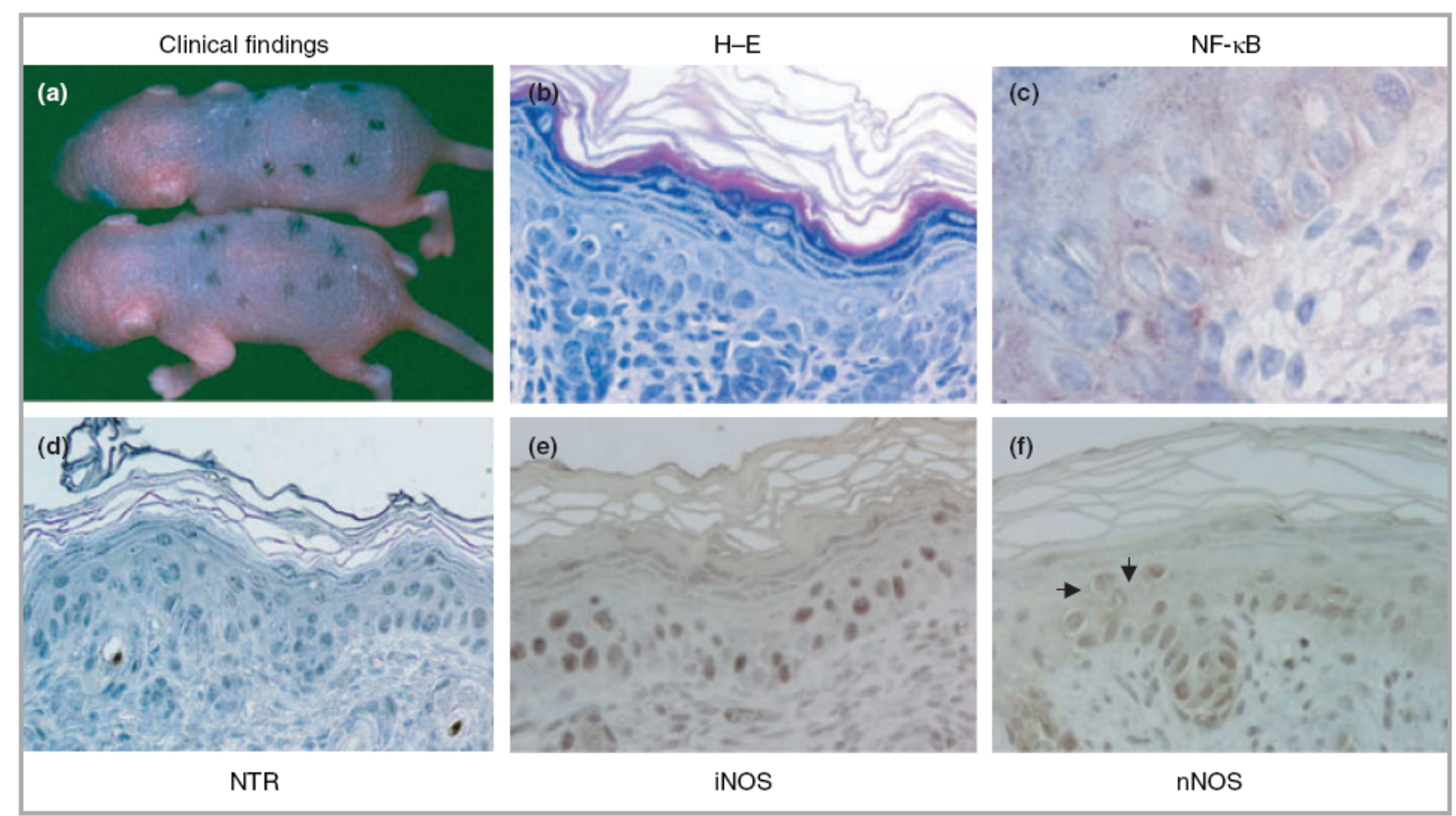

Figure 3. When mice were pretreated with genistein TK inhibitor before PV-IgG administration, clinical lesions (a) and suprabasal acantholysis (b) were not found. Additionally, no nuclear translocation of NF- $\mathrm{BB}$ (c) was found. NTR staining was absent (d) and scattered staining of nucleus of basal and suprabasal cells for iNOS (e) was detected, the same as those samples of epidermis of mice injected with NHS. A very slight basal cell cytoplasmic expression and scattered staining of nucleus for nNOS (arrow) (f) could be observed, without expression on the membrane of basal cells. Original magnification x 40 (b, d-f) and x 80 (c). 


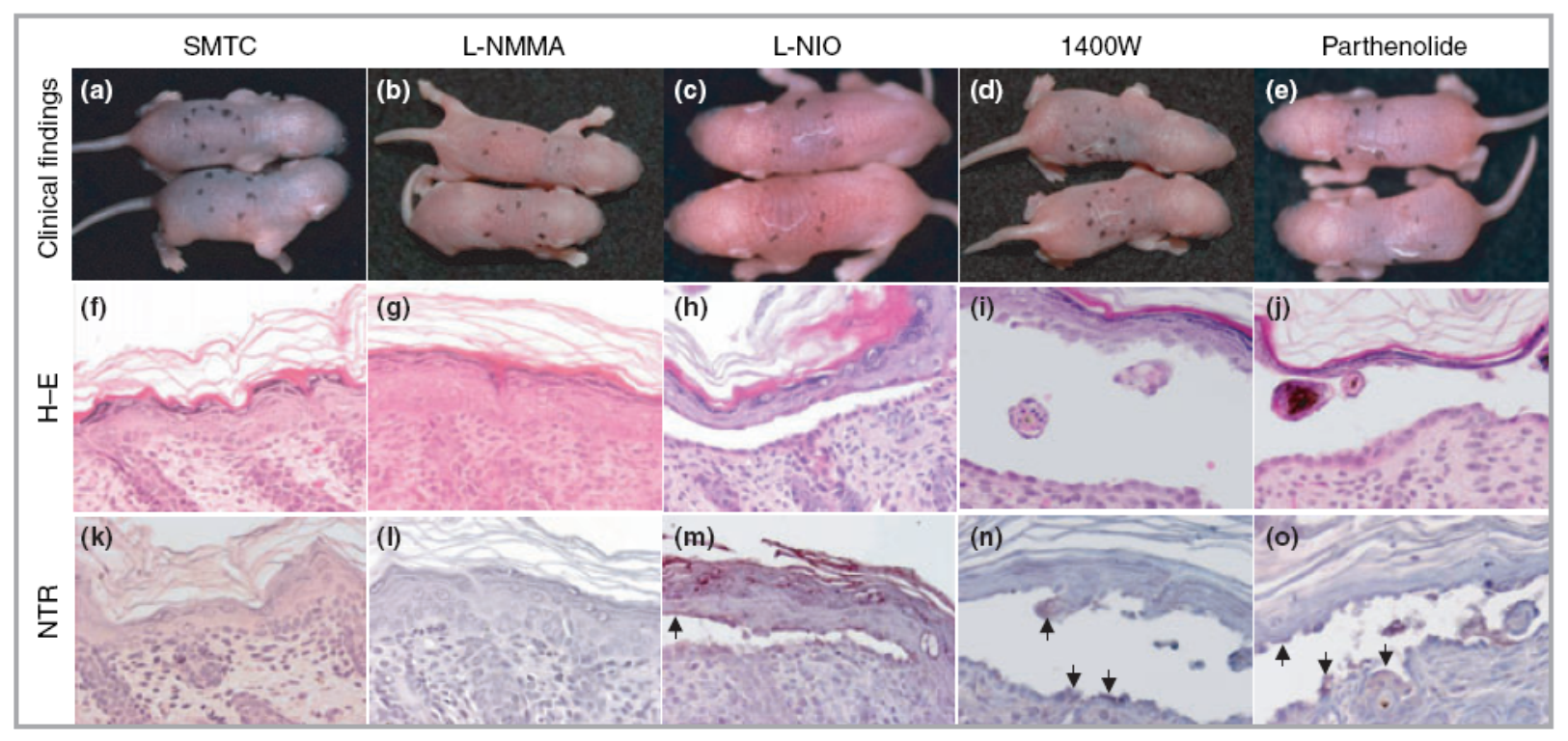

Figure 4. Clinical PV manifestations, suprabasal acantholysis and NTR expression were studied in mice pretreated with several inhibitors before PV-IgG injection. After administration of nNOS inhibitor SMTC $(a, f, k)$ and nonselective NOS inhibitor LNMMA (b, g, l) no clinical detachment, suprabasal blistering or NTR expression could be detected. In contrast, pretreatment with eNOS inhibitor L-NIO (c, h, m), iNOS inhibitor $1400 \mathrm{~W}(\mathrm{~d}, \mathrm{i}, \mathrm{n})$ and NF-kB inhibitor parthenolide $(\mathrm{e}, \mathrm{j}, \mathrm{o})$ did not abolish clinical and histological PV manifestations, and weak-moderate $(1+$ to $2+$, or $1+)$ NTR staining on the floor and base of membrane cells was found (arrow). PV-IgG, administration to mice of IgG fraction from PV patients; NHS, administration to mice of IgG fraction from normal human serum; NTR, expression of nitrotyrosine residues; eNOS, expression of endothelial nitric oxide synthase; iNOS, expression of inducible nitric oxide synthase; nNOS, expression of neuronal nitric oxide synthase; SMTC, nNOS inhibitor; L-NMMA, nonselective NOS inhibitor; L-NIO, eNOS inhibitor; $1400 \mathrm{~W}$, iNOS inhibitor; parthenolide, NF- $\kappa \mathrm{B}$ inhibitor. Original magnification $\mathrm{x} 40$ (fo). 